\title{
Four system boundaries for carbon accounts
}

\author{
Zhu Liu $^{\mathrm{a}, *}$, Kuishuang Feng ${ }^{\mathrm{b}}$, Klaus Hubacek ${ }^{\mathrm{b}}$, Sai Liang ${ }^{\mathrm{c}}$, Laura Diaz Anadon $^{\mathrm{a}}$, \\ Chao Zhang ${ }^{\mathrm{d}}$, Dabo Guan ${ }^{\mathrm{e}}$ \\ a John F. Kennedy School of Government, Harvard University, Cambridge, MA 02138, United States \\ ${ }^{\mathrm{b}}$ Department of Geographical Sciences, University of Maryland, College Park, MD 20742, United States \\ ' School of Natural Resources and Environment, University of Michigan, Ann Arbor, MI 48109-1041, United States \\ d School of Economics and Management, Tongji University, Shanghai 200092, China \\ e Tyndall Centre for Climate Change Research, School of International Development, University of East Anglia, Norwich, NR4 7TJ, United Kingdom
}

\section{A R T I C L E I N F O}

\section{Article history:}

Available online $\mathrm{xxx}$

\section{Keywords:}

Carbon emissions

Carbon footprint

Consumption-based emission

Multi-regional input-output analysis

Embodied emissions

China

\begin{abstract}
A B S T R A C T
Knowing the carbon emission baseline of a region is a precondition for any mitigation effort, but the baselines are highly dependent on the system boundaries for which they are calculated. On the basis of sectoral energy statistics and a nested provincial and global multi-regional input-output model, we calculate and compare four different system boundaries for China's 30 provinces and major cities. The results demonstrate significant differences in the level of emissions for the different system boundaries. Moreover, the associated emissions with each system boundary varies with the regional development level, i.e. richer areas outsource more emissions to other areas, or in other words boundary 4 emissions are higher than boundary 1 emissions for rich areas and vice versa for poor areas. Given these significant differences it is important to be aware of the implications the choice of an accounting system might have on outcomes.
\end{abstract}

(c) 2015 Elsevier B.V. All rights reserved.

\section{Introduction}

Climate change is an important factor impacting ecosystems in many ways. For example, global warming could force species to migrate to higher latitudes for survival (Thomas and Lennon, 1999) and lead to increased risk of extinction for species (Thomas et al., 2004). The IPCC in its fifth assessment report (AR5) affirmed that greenhouse gases (GHGs), in particular carbon dioxide emissions, from anthropogenic activities has been the dominant cause of the observed global warming since the mid-20th century (IPCC, 2001). Carbon as the basic element that supports living systems, is critical for the global ecology and human sustainability (Post et al., 1982). Carbon embodied in both organic and inorganic matter can be affected by natural process as well as anthropogenic activities, thus understanding the carbon flows within the human-environment nexus will help to promote human well-being while protecting the earth's living systems (Kyoto Protocol, 2010; Stern et al., 2006), and proper accounting for carbon becomes key.

Given that human induced carbon dioxide emissions are the major contributor to global warming, understanding regional and urban carbon flows becomes a precondition for the mitigation of

\footnotetext{
* Corresponding author. Tel.: +1 8587298727.

E-mail addresses: liuzhu@iae.ac.cn, zhu_liu@hks.harvard.edu (Z. Liu).
}

greenhouse gas emissions Energy consumption and carbon emission benchmarks are considered as an important step supporting regional carbon flow studies and carbon emission mitigation policies (Kennedy et al., 2009, 2011b). Recently, numerous low carbon energy development initiatives and emission mitigation actions have been introduced at regional and city levels in response to a lack of successful international negotiations on carbon emission mitigations for nations. More than a thousand cities and regions worldwide have pledged to reduce greenhouse gas (GHG) emissions at the local scale (Betsill and Bulkeley, 2006; International Council of Local Environmental Initiatives (ICLEI), 2008; Lenzen et al., 2004), regional mitigation actions such as "Cities for $\mathrm{Cli}$ mate Protection" (CCP)(Betsill and Bulkeley, 2004) and the "The C40 Cities Climate Leadership Group (C40)”(Román, 2010) are booming and the literature (Ramaswami et al., 2012) (Sovacool and Brown, 2010) on regional carbon emissions is growing quickly.

However, establishing appropriate and consistent system boundary and calculation processes for the calculation of carbon emissions remains challenging especially at the regional level. Regions can have varying boundaries of emission accounting depending on definitions and purpose of the analysis. Noncentralized or lacking statistics and huge discrepancies among economic development levels can lead to uncertainty with regard to carbon emissions (Sovacool and Brown, 2010). Moreover, regions have intensive interactions across system boundaries, such as 
domestic and international transportation, inter-regional electricity transmission and flows of other goods and services and purchased power supply generated outside the boundary, and those cross boundary activities can significantly affect the carbon emissions calculations dependent on the extent of boundary chosen (Liu et al., 2012c). The "carbon footprints" (Hammond, 2007; Hertwich and Peters, 2009; Minx et al., 2009; Weidema et al., 2008; Wiedmann and Minx, 2008), defined as the direct and indirect carbon emissions associated with consumption within a certain boundary, could contribute to upstream carbon emissions outside the boundary. Such "embodied emissions" or "consumption-based emissions" (Davis et al., 2011; Peters and Hertwich, 2008; Peters et al., 2012) will dramatically affect the regional emission baselines. For example, without considering the emission embodied in imports, carbon emission decreased in Beijing during 2008-2010, however Beijing's carbon footprint calculated by consumptionbased emissions shows a fast increase in the period (Feng et al., 2014).

Initiatives such as the Greenhouse Gas Protocol and International Council of Local Environmental Initiatives (ICLEI) suggested three different scopes of regional carbon emission: scope 1 emissions are referred to as territorial emissions (Kennedy et al., 2010, 2011b); scope 2 emissions are emissions embodied in electricity produced and imported or purchased from outside the boundary (International Council of Local Environmental Initiatives (ICLEI), 2008; Kennedy et al., 2010, 2011a; Liu et al., 2012c); and scope 3 emissions refer to emissions embodied in imported products and services (International Council of Local Environmental Initiatives (ICLEI), 2008; Kennedy et al., 2010, 2011a). Together with the "consumption based accounting" (emissions embodied in imports minus emissions embodied in exports) (Davis and Caldeira, 2010; Peters, 2008) which has been widely used for estimates of national carbon footprints, we identified 4 different system boundaries (Tables 1 and 2) for regional emission accounting:

System boundary 1: scope 1 emissions.

System boundary 2: scope $1+2$ emissions.

System boundary 3: scope $1+3$ emissions.

System boundary 4: consumption based emission (carbon footprint).

Research conducted based on scopes 1, 2, 3 and consumptionbased emissions have shown that in a globalized world, carbon emissions embodied in purchased electricity and imported goods and services could account for large proportions of carbon footprint of nations or regions, especially for more developed places outsourcing production and pollution (Davis et al., 2011; Feng et al., 2013; Guan et al., 2014b; Liu et al., 2012c). In addition, calculation of scope 2, and scope 3 emissions is widely used at the enterprise level and has become an important indicator for guiding low carbon policies and actions (Downie and Stubbs, 2013; World Resources Institute (WRI) and the World Business Council for Sustainable Development (WBCSD), 2014). There is also a booming literature using different scopes for regional carbon emission calculation (Hillman and Ramaswami, 2010; Liu et al., 2011; Minx et al., 2013; Peters, 2010). However, comparison of different regional emission accounting boundaries based on all the scope 1, 2, 3, and consumption based emissions are rarely conducted. In fact, different accounting boundaries have been widely used for regional carbon accounts (Kennedy et al., 2011b; Liu et al., 2012c; Ramaswami et al., 2012), thus the clear definition and comparison is urgent needed.

Understanding the effects of different system boundaries on carbon accounting at regional level (provincial level) is crucial for the carbon emissions mitigation and low carbon development in China, the largest carbon emitter, with its 2013 carbon emissions being higher than the emissions from the US and the EU together
(Global Carbon Project, 2014). China is now responsible for $50 \%$ of global coal consumption and for about $80 \%$ of the global annual increase of carbon emissions from fossil fuel consumption and cement production (Boden et al., 2013; Liu et al., 2013b) and thus plays a central role for mitigation of carbon emissions, globally. Regional carbon emissions baselines are especially important for China for a range of reasons: First, China is a vast country with significant spatial variations in its regional development, resource endowment and the environment. For example, the difference of carbon emission intensity (emissions per unit of economic output) among China's provinces is up to tenfold (Liu et al., 2012b). Secondly, sky-rocketing but differential carbon emission growth in China over the last decade resulted in the fact that carbon emissions in certain provinces could be equivalent to total emissions in major developed countries; for example, annual $\mathrm{CO}_{2}$ emissions in Shandong province are about 750 million tons in 2010 (Guan et al., 2012), equivalent to total annual emissions of Germany, the sixth largest emitter in the world. Finally and most importantly, the Chinese government has set itself the ambitious target of reducing the carbon intensity (carbon emission per unit of GDP) by $45 \%$ by 2020 against the level in 2005, this intensity targets act as China's central mitigation measures, directly allocated to individual provinces (Liu et al., 2013a). The research shows that more developed provinces perform better than under-developed provinces for achieving the intensity reduction targets, however such targets are mainly achieved by "outsourcing" manufacturing and pollution from developed regions to the underdeveloped regions (Feng et al., 2013), this could result in higher total emissions. In other words, China's current regional mitigation baselines only consider the system boundary 1 emissions, neglecting indirect emissions embodied in trade that reduce the regional system boundary 1 emissions in certain regions but contribute to the nation's total emissions.

The character of China's mitigation policy and emission status offers the opportunity to understand the impacts of different system boundary emissions on emission mitigation policy, by comparing them at the certain regions. Different system boundaries of carbon accounting leads to different policy strategies. In this study we calculated four different system boundaries emissions for China's 30 provinces (excluding Tibet and Taiwan) for 2007.

\section{Methods}

Cross-boundary exchange of energy supply, goods and services results in 4 different regional carbon emissions boundaries (see Tables 1 and 2 for the definition).

\subsection{Calculation of system boundary 1 emissions}

System boundary 1 carbon emissions refer to territorial emissions produced by fossil fuel combustion and industrial process. These are calculated by multiplying sectoral fossil fuel energy consumption by the associated emission factors (Guan et al., 2012):

$$
\begin{aligned}
\text { Emission }= & \sum \sum \sum\left(\text { Activity data }_{i, j, k}\right. \\
\times \text { Emission }_{\text {factor }}, j, k &
\end{aligned}
$$

Notes: $i$, fuel types; $j$, sectors; $k$, technology type.

\subsection{Calculation of system boundary 2 emissions}

System boundary 2 carbon emissions are system boundary 1 emissions plus the emissions from power generation of imported electricity. For calculating system boundary 2 emissions, the emission factor for imported electricity needs to be calculated by 
Table 1

Definition of scope 1-4 footprints.

\begin{tabular}{|l|l|l|l|l|}
\hline Components & $\begin{array}{l}\text { Emissions from in-boundary fossil fuel } \\
\text { combustion and industrial process }\end{array}$ & $\begin{array}{l}\text { Emissions } \\
\text { from } \\
\text { producing } \\
\text { exports }\end{array}$ & $\begin{array}{l}\text { Emissions } \\
\text { from } \\
\text { imported } \\
\text { electricity }\end{array}$ & $\begin{array}{l}\text { Emissions } \\
\text { embodied in } \\
\text { imports }\end{array}$ \\
\hline Scope 1 & & & & \\
\hline Scope 2 & & & & \\
\hline Scope 3 & & & & \\
\hline Scope 4 & & & & \\
\hline
\end{tabular}

Table 2

definition of system boundaries 1-4.

\begin{tabular}{l|llll|}
\hline & Scope 1 & Scope 2 & Scope 3 & Scope 4 \\
\hline System boundary 1 & & & & \\
System boundary 2 & & & & \\
System boundary 3 & & & & \\
System boundary 4 & & & & \\
\hline
\end{tabular}

considering the corresponding emissions of power generation. For China's power supply system, the electricity is supplied by regional grids, with current six grids covering 30 mainland provinces, thus the emission factors of electricity supplied by each grid could be calculated as:

Emission factor(electricity) $=\frac{\sum \text { Emission }_{l}}{\sum E_{l}}$

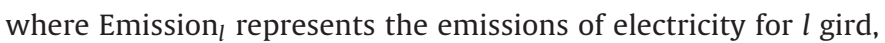
Emission $_{l}$ can be calculated by the aggregate of the emissions from provinces served by the $l$ state grid. $E_{l}$ is the total electricity supply for $l$ state grid, which contains the electricity from power plants, renewable energy (including wind, solar, hydro power and bio energy) and nuclear energy. The data of electricity consumption in 2007 is taken from 2008 Statistics Yearbook for each province; the calculation of direct emissions from power generation is based on the method for system boundary 1 carbon emissions.

Thus, emission embodied in imported electricity can be calculated by using the emission factor multiplied the import electricity.

\subsection{Calculation of system boundaries 3 and 4 emissions}

The system boundary 3 emission is the system boundary 1 emission plus the emissions embodied in imported products and services. The system boundary 4 emission is the system boundary 1 emission plus the emissions embodied in imports minus emissions embodied in exports. Thus the calculation of emissions embodied in imports and exports is critical for compiling system boundaries 3 and 4 emissions.

Environmentally extended multi-region input-output analysis (MRIO) analysis has been frequently adopted for calculation of international trade related emissions (Duchin, 1992; Hertwich and Peters, 2009; Peters and Hertwich, 2008; Shui and Harriss, 2006). In this study we adopt MRIO to calculate lifecycle (i.e. all upstream) emissions embodied in imports and exports.

In the MRIO framework, different regions are connected through inter-regional trade, $T^{r s}$. The technical coefficient sub-matrix $A^{r s}$ consists of $\left\{a_{i j}^{r S}\right\}$ and is given by $a_{i j}^{r s}=T_{i j}^{r s} / x_{j}^{S}$, in which $T_{i j}^{r s}$ is the intersector monetary flow from sector $i$ in region $r$ to sector $j$ in region $s ; x_{j}^{s}$ is the total output of sector $j$ in region $s$. The final demand matrix is $\left(y_{i}^{r s}\right)$, where $y_{i}^{r s}$ is the region's final demand for goods of sector $i$ from region $r$. Let $x=\left(x_{i}^{S}\right)$. Using familiar matrix notation and dropping the subscripts, thus

$A=\left[\begin{array}{cccc}A^{11} & A^{12} & \ldots & A^{1 n} \\ A^{21} & A^{22} & \ldots & A^{2 n} \\ \vdots & \vdots & \ddots & \vdots \\ A^{n 1} & A^{n 2} & \ldots & A^{n n}\end{array}\right] ; \quad y=\left[\begin{array}{c}\sum_{s} y^{1 s} \\ \sum_{s} y^{2 s} \\ \vdots \\ \sum_{s} y^{n s}\end{array}\right] ; \quad x=\left[\begin{array}{c}x^{1} \\ x^{2} \\ \vdots \\ x^{n}\end{array}\right]$

The MRIO framework can be written as

$x=A x+y$

By solving $x$ we have $(5) x=(I-A)^{-1} y$ where $(I-A)^{-1}$ is the Leontief inverse matrix captures the supply chain inputs to satisfy one unit of final demand in monetary value; $I$ is the identity matrix.

We extend the MRIO model with a vector of sectoral $\mathrm{CO}_{2}$ emission coefficients, $k$ :

$k=\left[\begin{array}{llll}k_{1} & k_{2} & \cdots & k_{n}\end{array}\right]$

Therefore, the total $\mathrm{CO}_{2}$ emissions embodied in goods and services used for final demand for all regions can be calculated by:

$\mathrm{CO}_{2}^{\text {tot }}=k(I-A)^{-1} y$

where $\mathrm{CO}_{2}^{\text {tot }}$ is the total $\mathrm{CO}_{2}$ emissions embodied in goods and services used for final demand; $k$ is a vector of $\mathrm{CO}_{2}$ emissions per unit of economic output for all economic sectors in all regions.

While Eq. (6) captures well the total life-cycle emissions associated with the final demand of a region, it may not be able to distinguish the emissions from domestic production and import. To calculate the emissions embodied in import of region $s$, we modify Eq. (6) to:

$\mathrm{CO}_{2}^{i m p}=k_{\sim s}(I-A)^{-1} y^{\cdot s}$

where $\mathrm{CO}_{2}^{i m p}$ is the total embodied emissions in import of region $s ; k_{\sim s}$ is a vector of sectoral $\mathrm{CO}_{2}$ emission coefficients for all other 


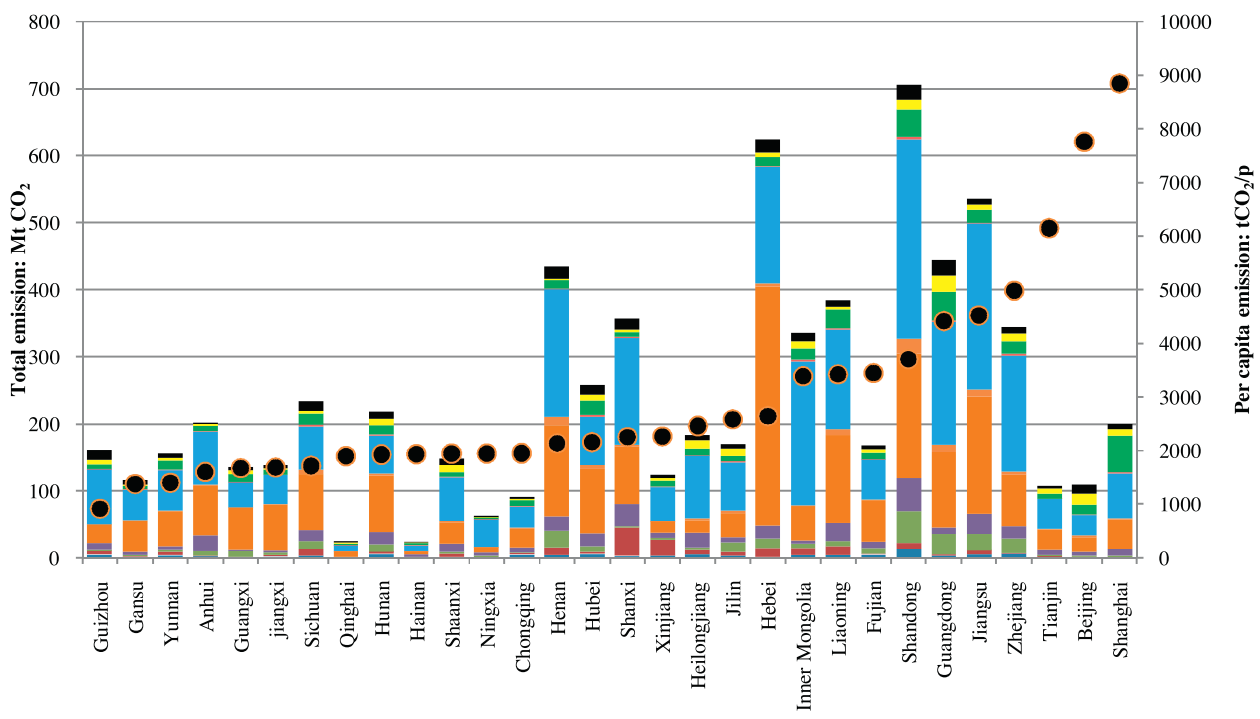

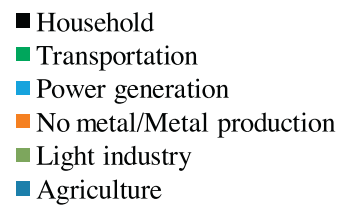

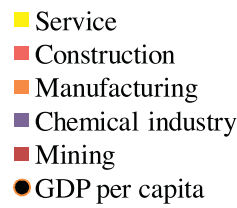

Fig. 1. System boundary 1 carbon emissions for China's 30 provinces.

regions but with zeros for the emission coefficients of region $s ; y^{s}$ is the final demand vector of region $s$ :

$\mathrm{CO}_{2}^{\exp }=k_{s}(I-A)^{-1} y^{s}$

where $\mathrm{CO}_{2}^{\text {exp }}$ is the total embodied emissions in export of region $s$; $k_{s}$ is a vector of sectoral carbon emission coefficients for the region $s$ but with zero for the emission coefficients of other regions; $y^{s}$. is the final demand vector of total sectoral final demand of other regions but excluding the final demand of region $s$.

Therefore, system boundary 3 emissions are the boundary 1 emissions plus the total embodied emissions in import, $\mathrm{CO}_{2}^{i m p}$. The system boundary 4 emissions are the total consumption-based carbon emissions: $\mathrm{CO}_{2}^{\text {tot }}$.

\subsection{Data sources}

Sectoral fossil fuel energy consumption data were taken from the 2008 Statistics Yearbook (National Bureau of Statistics of China, 1996-2012) from each province; in this research we consider 20 types of fossil fuels and 44 sectors. The clinker production data used for calculating cement production emission were taken from the Chinese Statistics Yearbook (National Bureau of Statistics, 2013); emissions of cement production for provinces are based on our previous emission estimates (Guan et al., 2012). The methodologies for conducting full inventories of China's provincial carbon emissions are consistent with previous research (Chen and Zhang, 2010; Liu et al., 2012b).

We adopted the global multi-regional input-output (MRIO) model from the Global Trade Analysis Project (GTAP, 2012) (Peters et al., 2011) which have data for 129 countries and regions with each region comprising 57 economic sectors. China's domestic MRIO comprises 30 sub-regions with 44 sectors for each region; China's domestic MRIO is compiled by Liu et al. (2012a) from Chinese Academy of Sciences. We aggregated the sectors and linked China's domestic MRIO with the global MRIO (Feng et al., 2013).

\section{Results}

\subsection{Boundaries 1-4 emissions of China's regions}

Total system boundary 1 emissions of 30 provinces are 7204 $\mathrm{Mt} \mathrm{CO}_{2}$ in 2007. East coast regions have higher system boundary 1 emissions. Shandong, Hebei, Jiangsu, Guangdong and Henan provinces together account for about $40 \%$ of national total system boundary 1 emissions. Shandong province has the highest boundary 1 emissions ( $726 \mathrm{Mt} \mathrm{CO}_{2}$ ), which would rank as No. 7 of global emitters. In terms of economic sectors, across provinces, power generation and metal/non-metal production take the lion's share ( $85 \%$ on average) of the total system boundary 1 carbon emissions, other emissions come from services (8\%), transportation (6\%) agriculture (2\%) and household consumption (4\%) (Fig. 1).

In terms of per capita system boundary 1 emission, less developed provinces such as Inner Mongolia, Shanxi and Ningxia have even higher per capita system boundary 1 emissions than richer cities such as Beijing and Shanghai. In addition, the emission intensity (emissions per unit GDP) in Inner Mongolia, Shanxi and Ningxia is several times of the level of more developed provinces (Municipalities) such as Beijing, Shanghai and Tianjin. Inner Mongolia, Shanxi and Ningxia are the energy and resources bases of China and these provinces produce carbon intensive inputs for the whole country. Half of the metal and cement and $40 \%$ of the electricity produced in Inner Mongolia are exported to other provinces. One quarter of China's coal is produced in Shanxi, while a large proportion is sold to other provinces. Moreover, economic growth of these provinces is mainly driven by capital investment in infrastructure (Guan et al., 2014a) contributing significantly to the high carbon intensive economy in these provinces.

In terms of system boundary 2 emissions, there are 11 provinces that import electricity from other regions with total emissions embodied in imported electricity accounting for $247 \mathrm{Mt} \mathrm{CO}_{2}$ (i.e. $9 \%$ of total emissions from power generation in China). Thus the system boundary 2 emissions are higher than in system 


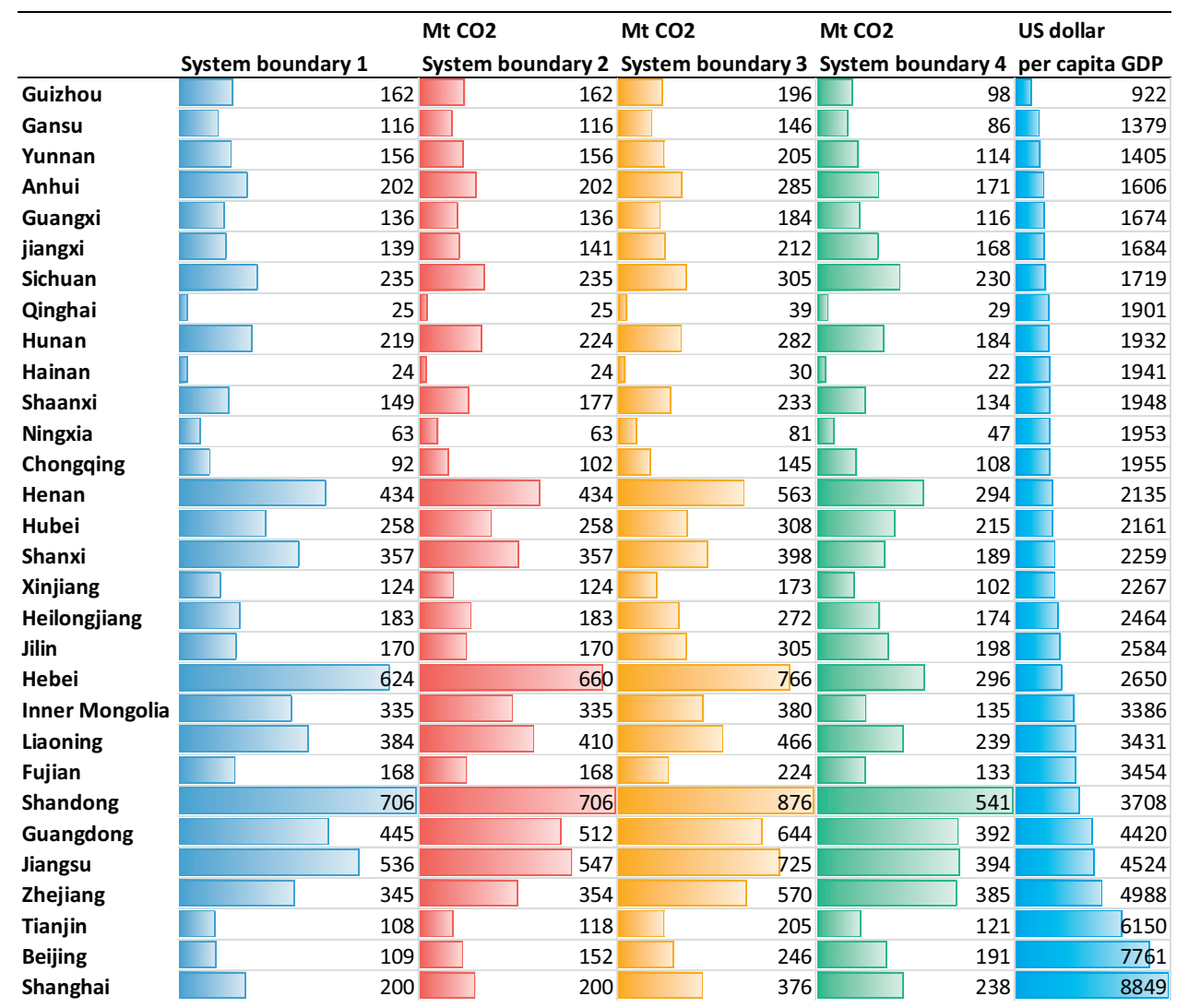

Fig. 2. Comparison of provincial system boundaries 1-4 carbon emissions.

boundary 1 emissions in these 11 provinces. In general the rich regions are major importers of electricity, top five richest provinces (measured by per capita GDP) together account for 50\% of total emissions embodied in cross-regional electricity transportation. This unbalanced inter-provincial emissions transfer is mainly driven by the geographic disparity of energy producers and energy consumers in China. China's developed coastal regions cannot achieve self-sufficiency of electricity, since most of the China's primary energy sources, especially coal reserves, are located in inland western regions; another factor is the associated air pollution that eastern provinces are avoiding through electricity imports. The "West to East Electricity Transmission" project, which promotes electricity production in western China to meet the soaring demand of eastern China, has been recognized as China's national energy development strategy. Inter-provincial transfer of electricity will certainly expand in the future and their share in the total carbon emissions of China's power sector will also be very much likely to increase, since many of China's new mega coal power plants are under construction in northwest regions (Zhang and Anadon, 2014; Zhang et al., 2014).

System boundary 3 emissions of 30 provinces account for $9837 \mathrm{Mt} \mathrm{CO}_{2}$ in 2007, which is equivalent to about $136 \%$ of the total system boundary 1 carbon emissions for the 30 provinces. This is caused by $2633 \mathrm{Mt} \mathrm{CO}_{2}$ that are embodied in imports, of which about $92 \%$ are from domestic imports and $8 \%$ from international imports. Among provinces, Shandong has the highest system boundary 3 emissions ( $876 \mathrm{Mt} \mathrm{CO}_{2}$ ). Again, the five richest provinces together account for $32 \%$ of total scope 3 emissions from 30 provinces.

System boundary 4 emissions account for $5764 \mathrm{Mt} \mathrm{CO}_{2}$ in 2007 , which is $20 \%$ less than the system boundary 1 emissions on average (Fig. 2). This implies that China's emissions embodied in exports are larger than the emissions embodied in imports. For provinces, only seven provinces (Shanghai, Beijing, Tianjin, Zhenjiang, Jiangxi, Chongqing and Jilin) with their system boundary 4 emissions higher than their system boundary 1 emissions, implies these regions are net emission importers. Shanghai, Beijing, Tianjin and Zhejiang as the top four richest regions (measured by per capita GDP) in China are the major importers of these trade embodied emissions. While the difference between system boundary 1 and system boundary 4 emissions is from the "net" emission embodied in trade, the four top richest regions (Shanghai, Beijing, Tianjin and Zhejiang) contributed $70 \%$ of the total difference $\left(1440 \mathrm{Mt} \mathrm{CO}_{2}\right)$ between system boundary 1 and system boundary 4 emissions. Particularly, system boundary 4 emissions for Beijing (the capital city with per capita GDP listed as the 2nd among 30 regions) could be twice of its system boundary 1 emissions. In contrast the system boundary 4 emissions are less than system boundary 1 emissions in less developed regions such as Yunnan, Guizhou, Qinghai and Ningxia as they are the net exporters of carbon intensive goods. This illustrates that the highly developed regions are the major 'consumers' of emissions embodied in trade.

Fig. 3 compares the trends of per capita emissions of system boundaries 1-4 emissions and GDP per capita. Ningxia, Shanxi and Inner Mongolia show every high per capita emission in both system boundaries 1-4 emissions due to their energy intensive economy.

To further uncover the relationship between the regional development (measured by per capita GDP) and the carbon emission from different boundaries (measured by per capita emission), we present regression analysis to show the relationship between per capita GDP and per capita system boundaries 1-4 emissions. The results show that the correlation with per capita GDP is gradually increasing from per capita system boundary 1 emission to per capita system boundary 4 emission (Fig. 4). This confirms findings from other studies (e.g. Prell et al., 2014; Davis and Caldeira, 2010; Feng et al., 2013) showing that rich countries/regions tend to 


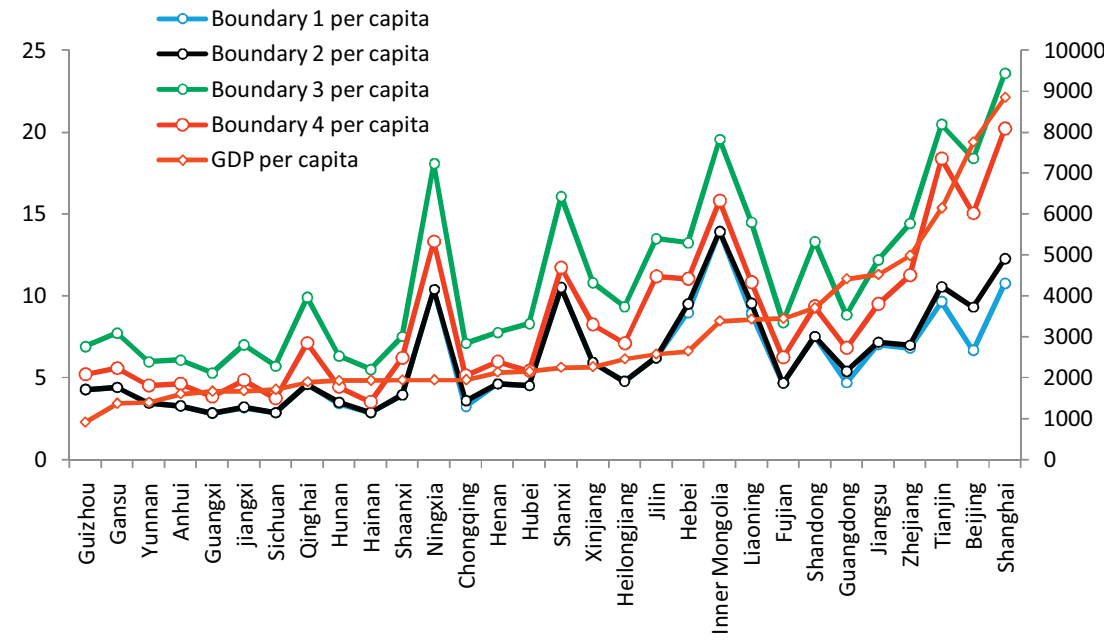

Fig. 3. Per capita emissions of system boundaries 1-4 and the per capita GDP for provinces.

import more emission intensive but low value added goods from poorer regions, outsourcing their emissions, which is also reflected in our results with higher per capita GDP in Chinese provinces having higher system boundaries 3 and 4 emissions per capita. In rich regions embedded emissions in imports account for up to $80 \%$ of the total consumption-based emissions of the region (e.g. Beijing and Shanghai) (Feng et al., 2014).

Due to the emissions embodied in imports and exports system boundary 3 emissions (scope $1+3$ ) are higher than system boundary 4 emissions (scope $1+3$-emission embodied in exports), system boundary 2 emission (scope $1+2$ ) and system boundary 1 emission (scope 1). The higher the development of a region and dependence on global supply chains and imports the higher the emissions associated with increasing system boundaries (Fig. 3).

\subsection{The impacts of different emission boundaries on China's regional emission targets}

Regional emission accounts provide important baselines for mitigation strategies. China allocates emission intensity targets for each individual province, and examines intensity reduction targets through its 5-Year Plans. These intensity reduction targets range
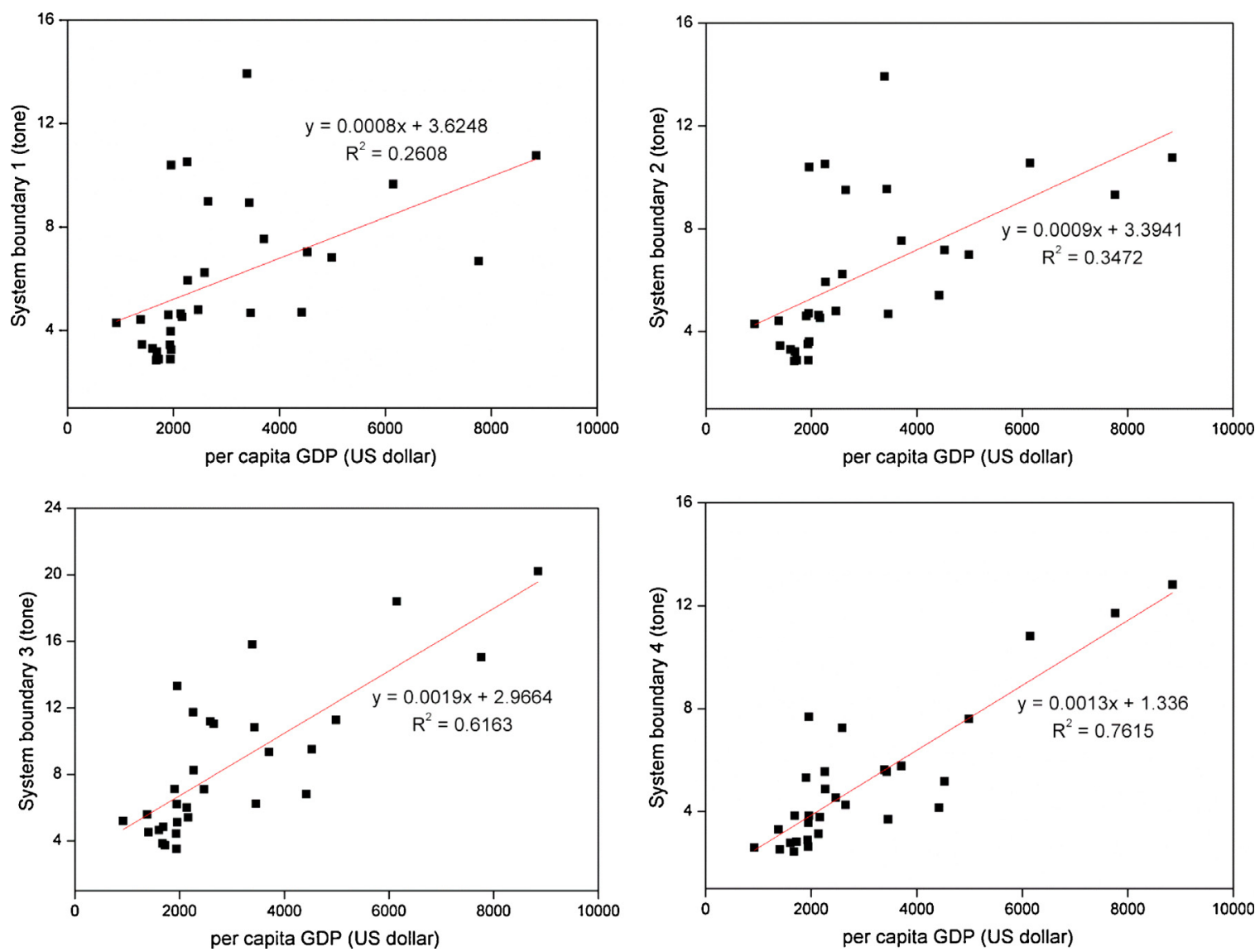

Fig. 4. Relationships between per capita GDP and per capita system boundaries 1-4 emissions.

Please cite this article in press as: Liu, Z., et al., Four system boundaries for carbon accounts. Ecol. Model. (2015), http://dx.doi.org/10.1016/j.ecolmodel.2015.02.001 
Table 3

Provincial emission intensity and targets.

\begin{tabular}{|c|c|c|c|c|c|c|c|}
\hline Province & $\begin{array}{l}\text { Intensity reduction } \\
\text { goal (2005-2010) } \\
(\%)\end{array}$ & $\begin{array}{l}\text { Intensity reduction } \\
\text { goal (2010-2015) } \\
(\%)\end{array}$ & $\begin{array}{l}\text { Intensity goal } \\
\text { achievement } \\
(2005-2010)(\%)\end{array}$ & $\begin{array}{l}\text { Intensity System } \\
\text { boundary } 1 \\
\left(\mathrm{tCO}_{2} / 1000 \text { dollar }\right)\end{array}$ & $\begin{array}{l}\text { Intensity System } \\
\text { boundary } 4 \\
\left(\mathrm{tCO}_{2} / 1000 \text { dollar }\right)\end{array}$ & $\begin{array}{l}\text { Difference of } \\
\text { intensity (\%) }\end{array}$ & $\begin{array}{l}\text { GDP/p (US \$ } \\
\text { per capita) }\end{array}$ \\
\hline Shanghai & 20 & 18 & 20.00 & 1.22 & 1.45 & 19.14 & 8848 \\
\hline Beijing & 20 & 17 & 26.59 & 0.86 & 1.51 & 75.05 & 7760 \\
\hline Tianjin & 20 & 18 & 21.00 & 1.57 & 1.76 & 12.03 & 6149 \\
\hline Zhejiang & 20 & 18 & 20.01 & 1.37 & 1.53 & 11.67 & 4988 \\
\hline Jiangsu & 20 & 18 & 20.45 & 1.55 & 1.14 & -26.47 & 4523 \\
\hline Guangdong & 16 & 18 & 16.42 & 1.06 & 0.94 & -11.74 & 4420 \\
\hline Shandong & 22 & 17 & 22.09 & 2.03 & 1.56 & -23.33 & 3707 \\
\hline Fujian & 16 & 16 & 16.45 & 1.36 & 1.07 & -20.90 & 3454 \\
\hline Liaoning & 20 & 17 & 20.01 & 2.61 & 1.62 & -37.94 & 3430 \\
\hline Inner Mongolia & 22 & 15 & 22.62 & 4.11 & 1.66 & -59.60 & 3385 \\
\hline Hebei & 20 & 17 & 20.11 & 3.39 & 1.61 & -52.60 & 2650 \\
\hline Jilin & 22 & 16 & 22.04 & 2.41 & 2.81 & 16.35 & 2584 \\
\hline Heilongjiang & 20 & 16 & 20.79 & 1.95 & 1.84 & -5.25 & 2463 \\
\hline Xinjiang & 12 & 10 & 12.00 & 2.62 & 2.15 & -17.76 & 2266 \\
\hline Shanxi & 22 & 16 & 20.66 & 4.66 & 2.46 & -47.21 & 2259 \\
\hline Hubei & 20 & 16 & 21.67 & 2.10 & 1.75 & -16.49 & 2160 \\
\hline Henan & 20 & 16 & 20.12 & 2.17 & 1.47 & -32.32 & 2134 \\
\hline Chongqing & 20 & 16 & 20.95 & 1.67 & 1.97 & 17.89 & 1954 \\
\hline Ningxia & 20 & 15 & 20.09 & 5.32 & 3.94 & -26.06 & 1953 \\
\hline Shaanxi & 20 & 16 & 20.25 & 2.04 & 1.83 & -10.03 & 1947 \\
\hline Hainan & 12 & 10 & 12.14 & 1.49 & 1.36 & -8.74 & 1940 \\
\hline Hunan & 20 & 16 & 20.43 & 1.78 & 1.50 & -15.65 & 1932 \\
\hline Qinghai & 17 & 10 & 17.04 & 2.42 & 2.79 & 15.22 & 1900 \\
\hline Sichuan & 20 & 16 & 20.31 & 1.68 & 1.64 & -2.09 & 1719 \\
\hline Jiangxi & 20 & 16 & 20.04 & 1.89 & 2.28 & 21.01 & 1684 \\
\hline Guangxi & 15 & 15 & 15.22 & 1.71 & 1.46 & -14.49 & 1674 \\
\hline Anhui & 20 & 16 & 20.36 & 2.06 & 1.74 & -15.52 & 1606 \\
\hline Tibet & 12 & 10 & 12.00 & No data & No data & Nodata & 1513 \\
\hline Yunnan & 17 & 15 & 17.41 & 2.46 & 1.80 & -26.64 & 1405 \\
\hline Gansu & 20 & 15 & 20.26 & 3.21 & 2.39 & -25.40 & 1379 \\
\hline Guizhou & 20 & 15 & 20.06 & 4.66 & 2.83 & -39.27 & 922 \\
\hline
\end{tabular}

within 5 percentage points (Table 3 ). For example, the eastern coast regions (such as Beijing and Shanghai) have been allocated intensity reduction of $20 \%$ in $2005-2010$, in contrast the central and western regions have been allocated intensity reduction of $15 \%$. However, by adopting system boundaries, the intensity difference of each region could be more than $70 \%$ in 2007 . For example, the system boundary 4 emission (footprints) in Inner Mongolia only equals to $40 \%$ of its system boundary 1 emissions. In contrast, the system boundary 4 emissions of Beijing equals to $175 \%$ of its system boundary 1 emissions. Thus the achievements of intensity reduction targets will be considerably different when using system boundaries 2, 3 or 4 emissions as baselines, instead of using system boundary 1 emissions.

As discussed above, the difference of emission system boundaries among rich and poor regions is mainly caused by emissions embodied in trade, illustrating "out-sourcing" of energy intensive manufacturing from developed regions to poorer regions but is also a fact of globalization and specialization. On the one hand, the outsourcing of manufacturing increases the spatial distance of the supply chain, thus further increase the emissions of the whole systems through moving production to places with lower labor costs and usually less efficient technologies and through increasing transport related emissions. On the other hand, the decrease of territorial emission from developed regions are bought at the expense of an increase of upstream emissions.

A practical problem is that, in most cases, consumption based emissions are out of control of local government, because large parts of consumption based emissions take place in other regions. But in order to avoid such leakages regional mitigation policies have to consider the emissions embodied in trade among regions. For the case of current mitigation policy in China, one supplementary measure could be to introduce the additional intensity reduction targets based on system boundaries 2-4 emissions, so the mitigation result by final demand energy saving and control approaches can be encouraged. For example, China issued the project on compiling the provincial carbon emissions inventories to server as the baseline for domestic cap and trade system, the emission embodied in import electricity has been considered as well. Comparing with current mitigation strategy that focuses on boundary 1 emissions, the additional perspective has advantages. First, the boundaries 2-4 accounting allocate more emission quota and associated mitigation responsibilities to the rich regions, where rich regions in general have more advanced technology and more efficient manufacturing, this could help to promote the total efficient of whole country. Secondly, considering the consumption (system boundaries 2-4) in addition to the production (system boundary 1) helps to mitigate the carbon emissions along the whole supply chain, and cost of emission mitigation can be reduced. For example, measured by system boundary 1 emissions, several provinces implemented electricity blackouts in 2009 in order to achieve the intensity reduction target for 2005-2010, while through the conservation measures of final consumer (for example, energy saving plan for household and government consumption), such blunt instrument can be avoid. Understanding 2-4 system boundary emissions is also crucial for highlighting the importance of demand-side efforts for carbon mitigation, e.g., energy and resources conservation by consumers, recycling and reuse of waste products, and shifting toward more sustainable lifestyles.

\section{Conclusions}

In this study, we explored 4 different system boundaries emissions for China's 30 provinces in 2007. The results show differences among different emissions boundaries. In general, the more developed regions tend to the net consumer of the emissions that embodied in trade, resulting in higher system boundaries 2-4 emissions compared to their system boundary 1 emissions. 
The different emission boundaries could dramatically affect the achievements of China's current regional mitigation targets. Our results show that measured by different system boundaries, the emission intensity could change up to $70 \%$ for certain regions, thus the achievement of regional intensity reduction targets under China's mitigation plan can be different. However, current mitigation baseline is based on system boundary 1 emissions and without considering the other boundaries. Thus, it is important to understand the multi-boundary emissions as the baselines for addressing mitigation policies.

\section{Acknowledgements}

Zhu Liu is a joint Giorgio Ruffolo fellow in the Sustainability Science Program in the Mossavar-Rahmani Center for Business and Government and Energy Technology Innovation Policy Fellow at the Belfer Center for Science and International Affairs, both at the Harvard University Kennedy School of Government. Support from Italy's Ministry for Environment, Land and Sea is gratefully acknowledged. Sai Liang thanks the support of the Dow Sustainability Fellows Program. This study was supported by the National Science Foundation of China (41328008, 41222036 and 71341025).

\section{References}

Betsill, M.M., Bulkeley, H., 2004. Transnational networks and global environmental governance: the cities for climate protection program. Int. Stud. Q. 48, 471-493.

Betsill, M.M., Bulkeley, H., 2006. Cities and the multilevel governance of global climate change. Glob. Gov. 12, 141-159.

Boden, T.A., Marland, G., Andres, R.J., 2013. Global, Regional, and National Fossil-Fuel $\mathrm{CO}_{2}$ Emissions. Oak Ridge National Laboratory, US Department of Energy.

Chen, G.Q., Zhang, B., 2010. Greenhouse gas emissions in China 2007: inventory and input-output analysis. Energy Policy 38, 6180-6193.

Davis, S.J., Caldeira, K., 2010. Consumption-based accounting of $\mathrm{CO}_{2}$ emissions. Proc. Natl. Acad. Sci. U. S. A. 107, 5687-5692.

Davis, S.J., Peters, G.P., Caldeira, K., 2011. The supply chain of $\mathrm{CO}_{2}$ emissions. Proc. Natl. Acad. Sci. U. S. A. 108, 18554-18559.

Downie, J., Stubbs, W., 2013. Evaluation of Australian companies' scope 3 greenhouse gas emissions assessments. J. Clean. Prod. 56, 156-163.

Duchin, F., 1992. Industrial input-output analysis: implications for industrial ecology. Proc. Natl. Acad. Sci. U. S. A. 89, 851-855

Feng, K., Davis, S.J., Sun, L., Li, X., Guan, D., Liu, W., Liu, Z., Hubacek, K., 2013. Outsourcing $\mathrm{CO}_{2}$ within China. Proc. Natl. Acad. Sci. U. S. A. 110, 11654-11659.

Feng, K., Hubacek, K., Sun, L., Liu, Z., 2014. Consumption-based $\mathrm{CO}_{2}$ accounting of China's megacities: the case of Beijing, Tianjin, Shanghai and Chongqing. Ecol. Indic. 47, 26-31.

Global Carbon Project, 2014. Carbon Budget 2014.

GTAP, 2012. GTAP 8 Data Base. Global Trade Analysis Project.

Guan, D., Liu, Z., Geng, Y., Lindner, S., Hubacek, K., 2012. The gigatonne gap in China's carbon dioxide inventories. Nat. Clim. Change, 672-675.

Guan, D., Klasen, S., Hubacek, K., Feng, K., Liu, Z., He, K., et al., 2014a. Determinants of stagnating carbon intensity in China. Nat. Clim. Change 4 (11), 1017-1023.

Guan, D., Su, X., Zhang, Q., Peters, G.P., Liu, Z., Lei, Y., He, K., 2014b. The socioeconomic drivers of China's primary PM2.5 emissions. Environ. Res. Lett. 9, 024010

Hammond, G., 2007. Time to give due weight to the 'carbon footprint' issue. Nature $445,256$.

Hertwich, E.G., Peters, G.P., 2009. Carbon footprint of nations: a global, trade-linked analysis. Environ. Sci. Technol. 43, 6414-6420.

Hillman, T., Ramaswami, A., 2010. Greenhouse gas emission footprints and energy use benchmarks for eight US cities. Environ. Sci. Technol. 44, 1902-1910.

Intergovernmental Panel on Climate Change (IPCC), 2001. Climate change 2001: The scientific basis. Third Assessment Report of the Intergovernmental Panel on Climate Change Cambridge Univ Press.

International Council of Local Environmental Initiatives (ICLEI), 2008. Cities for Climate Protection.

Kennedy, C., Steinberger, J., Gasson, B., Hansen, Y., Hillman, T., Havranek, M., Pataki, D., Phdungsilp, A., Ramaswami, A., Mendez, G.V., 2009. Greenhouse gas emissions from global cities. Environ. Sci. Technol. 43, 7297-7302.

Kennedy, C., Steinberger, J., Gasson, B., Hansen, Y., Hillman, T., Havránek, M., Pataki, D., Phdungsilp, A., Ramaswami, A., Mendez, G.V., 2010. Methodology for inventorying greenhouse gas emissions from global cities. Energy Policy 38, 48284837.
Kennedy, C.A., Ramaswami, A., Carney, S., Dhakal, S., 2011a. Greenhouse gas emission baselines for global cities and metropolitan regions. In: Cities and Climate Change: Responding to an Urgent Agenda., pp. 15-54.

Kennedy, C.A., Ramaswami, A., Carney, S., Dhakal, S., 2011b. Greenhouse Gas Emission Baselines for Global Cities and Metropolitan Regions. The World Bank, pp. 15.

Kyoto Protocol, 2010. Framework Convention on Climate Change.

Lenzen, M., Dey, C., Foran, B., 2004. Energy requirements of Sydney households. Ecol. Econ. 49, 375-399.

Liu, Z., Geng, Y., Xue, B., 2011. Inventorying energy-related $\mathrm{CO}_{2}$ for city: Shanghai study. Energy Procedia, 2303-2307.

Liu, W., Chen, J., Tang, Z., Liu, H., Han, D., Li, F., 2012a. Therories and Practice of Constructing China's Interregional Input-Output Tables between 30 Provinces in 2007. China Statistics Press, Beijing.

Liu, Z., Geng, Y., Lindner, S., Guan, D., 2012b. Uncovering China's greenhouse gas emission from regional and sectoral perspectives. Energy 45, 1059-1068.

Liu, Z., Liang, S., Geng, Y., Xue, B., Xi, F., Pan, Y., Zhang, T., Fujita, T., 2012c. Features, trajectories and driving forces for energy-related GHG emissions from Chinese mega cites: the case of Beijing, Tianjin, Shanghai and Chongqing. Energy 37, 245-254.

Liu, Z., Guan, D., Crawford-Brown, D., Zhang, Q., He, K., Liu, J., 2013a. Energy policy: a low-carbon road map for China. Nature 500, 143-145.

Liu, Z., Guan, D., Crawford-Brown, D., Zhang, Q., He, K., Liu, J., 2013b. A low-carbon road map for China. Nature 500, 143-145.

Minx, J., Wiedmann, T., Wood, R., Peters, G.P., Lenzen, M., Owen, A., Scott, K., Barrett J., Hubacek, K., Baiocchi, G., 2009. Input-output analysis and carbon footprinting: an overview of applications. Econ. Syst. Res. 21, 187-216.

Minx, J., Baiocchi, G., Wiedmann, T., Barrett, J., Creutzig, F., Feng, K., Förster, M. Pichler, P.-P., Weisz, H., Hubacek, K., 2013. Carbon footprints of cities and other human settlements in the UK. Environ. Res. Lett. 8, 035039.

National Bureau of Statistics of China, 1996-2012. China Statistical Yearbook.

National Bureau of Statistics, 2013. China Statistical Yearbook 2013. China Statistics Press, Beijing.

Peters, G.P., 2008. From production-based to consumption-based national emission inventories. Ecol. Econ. 65, 13-23.

Peters, G.P., 2010. Carbon footprints and embodied carbon at multiple scales. Curr. Opin. Environ. Sustain. 2, 245-250.

Peters, G.P., Hertwich, E.G., 2008. $\mathrm{CO}_{2}$ embodied in international trade with implications for global climate policy. Environ. Sci. Technol. 42, 1401-1407.

Peters, G.P., Andrew, R., Lennox, J., 2011. Constructing an environmentally-extended multi-regional input-output table using the GTAP database. Econ. Syst. Res. 23 , $131-152$.

Peters, G.P., Marland, G., Le Quéré, C., Boden, T., Canadell, J.G., Raupach, M.R., 2012. Rapid growth in $\mathrm{CO}_{2}$ emissions after the 2008-2009 global financial crisis. Nat. Clim. Change 2, 2-4.

Post, W.M., Emanuel, W.R., Zinke, P.J., Stangenberger, A.G., 1982. Soil Carbon Pools and World Life Zones.

Prell, C.K.F., Sun, L., Geores, M., Hubacek, K., 2014. The global economic gains and environmental losses of US consumption: a world-systems and input-output approach. Soc. Forces 93, 405-428.

Ramaswami, A., Chavez, A., Chertow, M., 2012. Carbon footprinting of cities and implications for analysis of urban material and energy flows. J. Ind. Ecol. 16, $783-785$.

Román, M., 2010. Governing from the middle: the C40 Cities Leadership Group. Corp. Gov. 10, 73-84.

Shui, B., Harriss, R.C., 2006. The role of $\mathrm{CO}_{2}$ embodiment in US-China trade. Energy Policy 34, 4063-4068.

Sovacool, B.K., Brown, M.A., 2010. Twelve metropolitan carbon footprints: a preliminary comparative global assessment. Energy Policy 38, 4856-4869.

Stern, N.H., Britain, G., Treasury, H., 2006. Stern Review: The Economics of Climate Change. HM Treasury, London.

Thomas, C.D., Lennon, J.J., 1999. Birds extend their ranges northwards. Nature 399 213.

Thomas, C.D., Cameron, A., Green, R.E., Bakkenes, M., Beaumont, L.J., Collingham, Y.C., Erasmus, B.F.N., de Siqueira, M.F., Grainger, A., Hannah, L., Hughes, L., Huntley, B., van Jaarsveld, A.S., Midgley, G.F., Miles, L., Ortega-Huerta, M.A., Townsend Peterson, A., Phillips, O.L., Williams, S.E., 2004. Extinction risk from climate change. Nature 427, 145-148.

Weidema, B.P., Thrane, M., Christensen, P., Schmidt, J., Løkke, S., 2008. Carbon footprint. J. Ind. Ecol. 12, 3-6.

Wiedmann, T., Minx, J., 2008. A definition of 'carbon footprint'. In: Pertsova, C.C. (Ed.) Ecological Economics Research Trends. Nova Science Publishers, Hauppauge, NY, USA, pp. 1-11.

World Resources Institute (WRI), World Business Council for Sustainable Development (WBCSD), 2014. The Greenhouse Gas Protocol (GHG Protocol).

Zhang, C., Anadon, L.D., 2014. A multi-regional input-output analysis of domestic virtual water trade and provincial water footprint in China. Ecol. Econ. 100, $159-172$.

Zhang, C., Anadon, L.D., Mo, H., Zhao, Z., Liu, Z., 2014. Water-carbon trade-off in China's coal power industry. Environ. Sci. Technol. 48 (19), 11082-11089. 